Jurnal Pemberdayaan: Publikasi Hasil Pengabdian kepada Masyarakat

Vol. 3, No. 2, Agustus 2019, Hal. 137-144

ISSN: 2580-2569; e-ISSN: 2656-0542

DOI: https://doi.org/10.12928/jp.v3i2.598

\title{
Pendampingan masyarakat Serut, Kayoman, dan Dawung memaksimalkan potensi masyarakat di bidang keagamaan, pendidikan, dan ekonomi
}

\author{
Surahma Asti Mulasari, Muhson Syehab, Tri Kusuma Dewi, Awhinarto \\ Universitas Ahmad Dahlan, Jalan Prof. Dr. Soepomo, S.H. Janturan Yogyakarta 55164 \\ Email: surahma.mulasari@ikm.uad.ac.id
}

\begin{abstract}
ABSTRAK
Pada Dusun Serut, Dusun Kayoman, dan Dusun Dawung terjadi problematika yang berkaitan dengan bidang ekonomi dan juga pendidikan, baik pendidikan formal maupun pendidikan non formal (TPA). Dalam bidang ekonomi, masyarakat sudah mampu memproduksi bahan mentah menjadi makanan, namun masyarakat mengalami kesulitan untuk memperoleh bahan baku di wilayahnya sendiri dan kendala pemasaran produk sehingga masyarakat belum mampu mengangkat dan mengembangkan produktifitas serta harga jual produk tersebut. Dalam tingkat pendidikan, jenjang pendidikan formal sebagian besar masyarakat hanya menempuh pendidikan sampai di tingkat Sekolah Menengah Pertama. Sedangkan dalam hal pendidikan non formal (TPA), di ketiga dusun tersebut TPA juga belum terlaksana secara rutin. Tujuan program Kuliah Kerja Nyata (KKN) Universitas Ahmad Dahlan (UAD) di dusun Serut, Kayoman, dan Dawung mempunyai fokus pemberdayaan di bidang ekonomi, pendidikan, dan juga keagamaan. Dimana ketiga hal tersebut, merupakan hal yang sangat mendasar untuk memberdayakan masyarakat yang nantinya baik dalam hal keduniaan maupun hal yang berkaitan dengan ke-Tuhanan. Metode pelaksanaan yang dilakukan adalah penyuluhan dan pendampingan Diharapkan dengan adanya hal tersebut, bisa mengubah mindset masyarakat yang semula belum mempunyai keberanian untuk memasarkan potensi secara lebih luas. Selain itu, masyarakat bisa memajukan daerahnya sendiri, terutama untuk memajukan dalam hal ekonomi masyarakat setempat.
\end{abstract}

Kata kunci : program kerja, pemberdayaan, potensi, masyarakat

\begin{abstract}
Serut Hamlet, Kayoman Hamlet, and Dawung Hamlet, there was problems related to the economy and also education, both formal and non-formal education (TPA). In the economic field, the community has been able to produce raw materials into food, but the community has difficulty in obtaining raw materials in its own area and product marketing constraints so that people have not been able to raise and develop the productivity and selling prices of these products. In the level of education, most formal education levels of society only go to the junior high school level. Whereas in the case of non-formal education (TPA), in the three hamlets the TPA has also not been carried out routinely. The purpose of Ahmad Dahlan University's (KKN) Community Service (KKN) program in Serut, Kayoman, and Dawung hamlets has a focus on empowerment in the fields of economics, education, and also religion. Where these three things are very basic things to empower people who will be both worldly and things related to Godhead. The method of implementation carried out was counseling and mentoring. It was hoped that with this, it could change the mindset of the people who had not yet had the courage to market their potential more broadly. In addition, the community can advance its own area, especially to advance in terms of the economy of the local community.
\end{abstract}

Keywords : work plan, empowerment, society, potential 


\section{PENDAHULUAN}

Dusun Serut, Dusun Kayoman, dan Dusun Dawung, merupakan tiga dusun dari tujuh dusun yang berada di wilayah pemerintahan desa Serut, kecamatan Gedangsari, kabupaten Gunungkidul, provinsi Daerah Istimewa Yogyakarta. Ketiga dusun tersebut, memiliki kondisi geografis berupa dataran tinggi. Dimana mayoritas masyarakat bermatapencaharian sebagai petani. Secara umum, problematika yang terjadi di ketiga dusun tersebut tidak jauh berada. Yaitu, berkaitan dengan bidang ekonomi dan juga pendidikan, baik pendidikan formal maupun pendidikan non formal (TPA).

Dalam bidang ekonomi, pada dasarnya masyarakat sudah mempunyai potensi yang baik. Masyarakat sudah mampu memproduksi bahan mentah menjadi makanan ringan seperti keripik pisang, pudding ubi ungu, dan lain sebagainya. Ditambah lagi dengan alat produksi yang juga sudah tersedia. Hanya saja, yang menjadi permasalahan yaitu untuk memperoleh bahan baku, masyarakat masih mengalami kendala. Kendala tersebut antara lain, masyarakat mengalami kesulitan untuk memperoleh bahan baku di wilayahnya sendiri. Yang menjadikan masyarakat harus membeli bahan baku di wilayah kota Jogja atau yang terdekat yaitu di Klaten. Itupun masyarakat harus membeli bahan baku dengan harga yang tidak murah.

Selain itu, masyarakat juga masih terkendala dalam pemasaran produk tersebut. Masyarakat hanya memasarkan produknya dengan cara dititipkan di warung-warung sekitar. Dengan hal tersebut, belum mampu mengangkat dan mengembangkan produktifitas serta harga jual produk masyarakat tersebut.

Dalam tingkat pendidikan, di ketiga dusun tersebut masih rendah, baik pendidikan formal maupun non formal (TPA). Dalam jenjang pendidikan formal, sebagian besar hanya sampai di tingkat Sekolah Menengah Pertama (SMP). Untuk yang melanjutkan ke tingkat pendidikan yang lebih tinggi, jumlahnya masih bisa dihitung dengan jari. Umumnya, para pemuda lebih memilih mengadu nasib di tanah perantauan. Salah satu yang mendasari hal tersebut juga salah satunya adalah dalam aspek ekonomi.

Dalam hal pendidikan non formal (TPA). Di ketiga dusun tersebut juga belum terlaksana secara rutin. Bahkan boleh dikatakan TPA hanya berjalan ketika ada program Kuliah Kerja Nyata (KKN) di wilayah tersebut. Hal tersebut disebabkan oleh tidak adanya tenaga pendidik TPA di wilayah tersebut. Untuk melaksanakan TPA secara rutin, anak-anak harus menempuh jarak yang cukup jauh menuju ke dusun tetangga.

Dengan adanya bebarapa hal tersebut di atas. Program Kuliah Kerja Nyata (KKN) Universitas Ahmad Dahlan (UAD) di Dusun Serut, Kayoman, dan Dawung. Mempunyai fokus pemberdayaan di bidang ekonomi, pendidikan, dan juga keagamaan. Dimana ketiga hal tersebut, merupakan hal yang sangat mendasar untuk memberdayakan masyarakat yang nantinya baik dalam hal keduniaan maupun hal yang berkaitan dengan ke-Tuhanan.

\section{METODE}

Metode yang dilakukan yaitu dengan cara melakukan penyuluhan, pelatihan, dan pendampingan masyarakat. Penyuluhan dilakukan agar nantinya masyarakat sadar akan potensi yang masyarakat miliki. Pelatihan untuk meningkatkan keterampilan dan pengetahuan masyarakat. Pendampingan dilakukan agar nantinya masyarakat bisa ikut serta memaksimalkan potensinya, bisa mandiri dan tidak ketergantungan ketika mahasiswa KKN sudah selesai menjalankan tugas atau tidak ada program KKN di wilayah setempat.

Mahasiswa peserta KKN berjumlah 27 orang dibagi ke dalam tiga unit XIV.C.1, XIV.C.2, dan XIV.C.3 dengan mahasiswa sembilan orang/dusun yaitu Dusun Serut, Kanyoman, dan Dawung. Adapun tahapan kegiatan yang dilakukan meliputi:

1. Road Show Pengajian (Pengajian keliling)

2. Pendampingan dan pengembangan bakat anak berbasis masjid

3. Pendampingan produksi dan pemasaran produk lokal. 
Kuliah Kerja Nyata Universitas Ahmad Dahlan Periode 71, dilaksanakan 30 hari efektif di lapangan. Terhitung sejak penerjunan pada tanggal 25 Januari 2019 sampai dengan penarikan pada tanggal 22 Februari 2019.

\section{HASIL, PEMBAHASAN, DAN DAMPAK}

Program kerja yang dilaksanakan mencakup empat bidang yaitu, bidang keilmuan, bidang keagamaan, bidang seni dan olahraga, serta bidang tematik dan non tematik. Keempat bidang tersebut kemudian dibagi menjadi dua yaitu program individu dan juga program bersama. Program bidang keilmuan wajib dilaksanakan sesuai dengan keilmuan dan program studi dari masing-masing mahasiswa yang bersangkutan. Bidang keagamaan merupakan sebuah komitmen UAD yang merupakan perguruan tinggi berbasis agama Islam dan sekaligus menjadi salah satu AUM (Amal Usaha Muhammadiyah) di bawah naungan persyarikatan Muhammadiyah yang harus senantiasa berada dijalur dakwah kepada umat agar kembali kepada Al-Qur'an dan Sunnah nabi Muhammad SAW.

Bidang seni dan olahraga bertujuan agar masyarakat Indonesia tidak lupa dengan budaya lokal Indonesia, serta berupaya agar masyarakat terbiasa dengan berolahraga. Jika masyarakat gemar olahraga diharapkan masyarakat akan sehat dan kuat. Ketika masyarakat sudah sehat dan kuat bukan tidak mungkin masyarakat akan lebih semangat dalam memajukan daerahnya masing-masing. Dan program yang terakhir yaitu program yang masuk dalam bidang tematik dan non tematik. Dimana bidang ini dilaksanakan berdasarkan kebutuhan dan permasalahan masyarakat setempat.

Sebagai bentuk pemberdayaan kepada masyarakat di bidang ekonomi, pendidikan dan keagamaan. Peserta KKN UAD periode 71 unit XIV.C.1, XIV.C.2, dan XIV.C.3 melakukan pengedukasian dan pendampingan dengan program-program yang telah direncanakan. Antara lain yaitu:

\section{Road Show Pengajian (Pengajian Keliling)}

Masa remaja adalah bagian dari tahap perkembangan hidup setiap manusia. Perubahan zaman menyebabkan Krisis moral yang semakin memprihatinkan pada para remaja, hal ini merupakan kekhawatiran yang benar-benar harus diperhatikan dengan sungguh-sungguh (Zulmaron dkk, 2017). Salah satu upaya penyelamatan generasi muda adalah dengan menanamkan nilai-nilai Islam, oleh karena itu mahasiswa KKN UAD bersama pemuda Desa Serut bekerjasama dan mengadakan kegiatan road show pengajian.

Road show pengajian merupakan pengajian keliling dari masjid ke masjid yang dilakukan oleh para pemuda di Dusun Serut dimana tema yang diangkat yaitu seputar kajian kepemudaan. Pemuda adalah aktor kunci dalam sebagian besar proses perubahan (Naafs \& White, 2012). Dengan adanya kegiatan Road show pengajian diharapkan dapat menyiapkan pemuda sebagai generasi penerus bangsa yang tetap berlandaskan agama Islam. Kegiatan Road Show terlihat pada gambar 1.
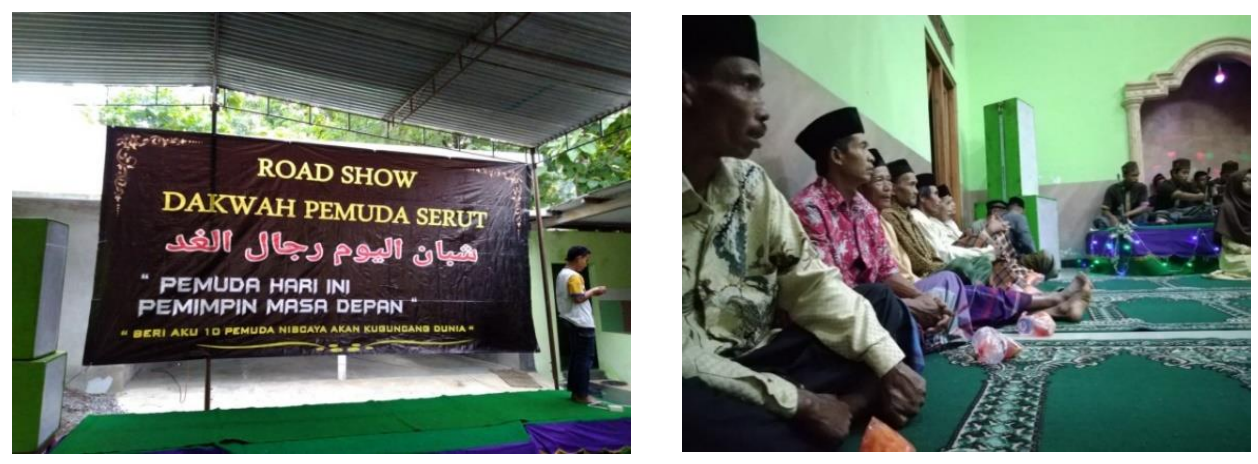

Gambar 1 Kegiatan road show pengajian 
Selain kegiatan pengajian, pemuda Dusun Serut juga diberikan edukasi mengenai pendidikan agama islam. Pendidikan Agama Islam diharapkan mampu menghasilkan manusia yang selalu berupaya menyempurnakan iman, takwa, dan berakhlak mulia, mencakup etika, budi pekerti, atau moral sebagai perwujudan dari pendidikan (Ainiyah, 2013).Salah satu pendidikan agama islam yang diberikan adalah pelatihan perawatan jenazah. Hal tersebut sangat dibutuhkan oleh masyarakat, karena sebelumnya masyarakat harus membayar jasa ketika ada masyarakat setempat yang meninggal dunia. Kegiatan pelatihan jenazah terlihat pada gambar 2 .

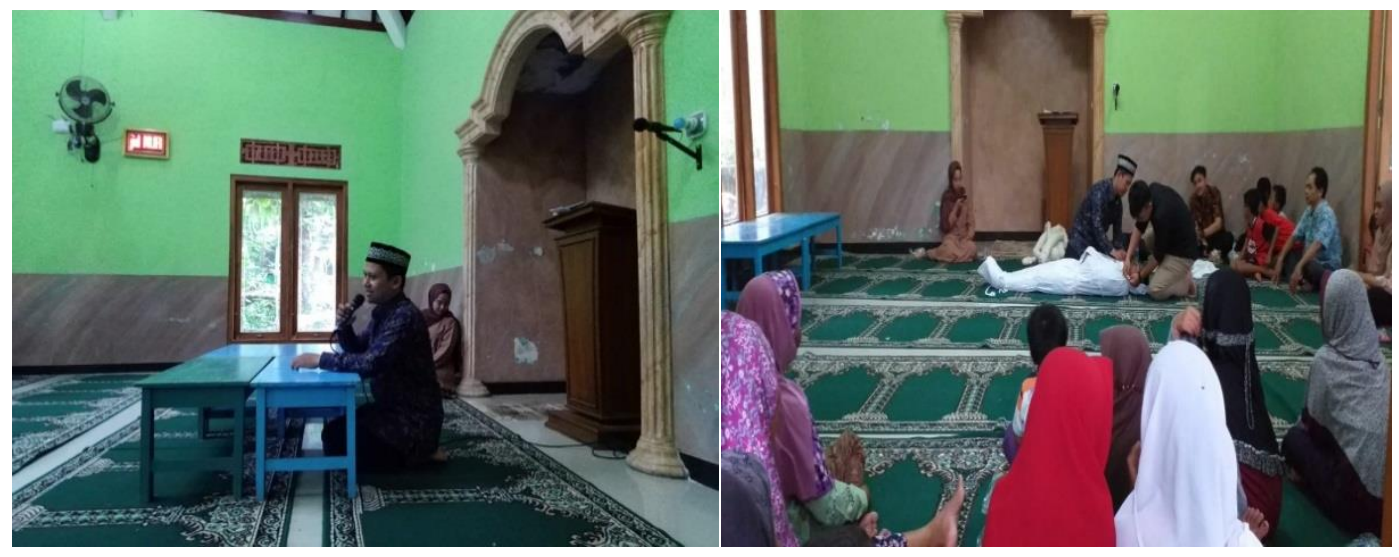

Gambar 2 Kegiatan pelatihan perawatan jenazah

\section{Pendampingan Bakat Anak Berbasis Masjid}

Fenomena yang terjadi di lokasi KKN yaitu masjid bisa dikatakan sepi dari masyarakat dan anak-anak. Masjid adalah institusi yang inheren dengan masyarakat Islam (Nugraha, 2010). Masjid sebagai tempat hamba mengekspresikan keimanannya kepada Allah SWT, melaksanakan ibadah kepada-Nya dan berbuat ihsan atas nama-Nya (Darodjat \& Wahyudiana, 2014).

Pada masa Rasulullah masjid tidak hanya sebatas tempat shalat saja, atau tempat berkumpulnya kelompok masyarakat (kabilah) tertentu, melainkan masjid menjadi sentra utama seluruh aktivitas keumatan, yaitu sentra pendidikan, politik, ekonomi, sosial dan budaya (Kurniawan, 2014). Berangkat dari fenomena di atas, dan juga untuk menggali dan megembangkan bakat anak di tempat KKN. Mahasiswa KKN memilih masjid sebagai tempat berlangsungnya kegiatan pendampingan.

Salah satu kegiatan yang dilakukan adalah pendampingan baca-tulis Al-Quran. Al Qur'an adalah sumber hukum pertama dan utama bagi umat Islam (Kurniawan, 2014). Pendidikan Al-Qur'an bagi anak-anak merupakan masalah yang harus mendapat perhatian bila ingin melihat generasi baru yang tangguh, beriman, dan berakhlak mulia. Mendidik anak-anak dengan aksara dan jiwa Al Quran, berupa pemahaman, penghayatan, pengamalan Al-Qur'an serta kajian-kajian Islam dapat menjadi anak-anak ummat Islam menjadi generasi idaman dan harapan di masa depan (Muntoha dkk., 2015). 

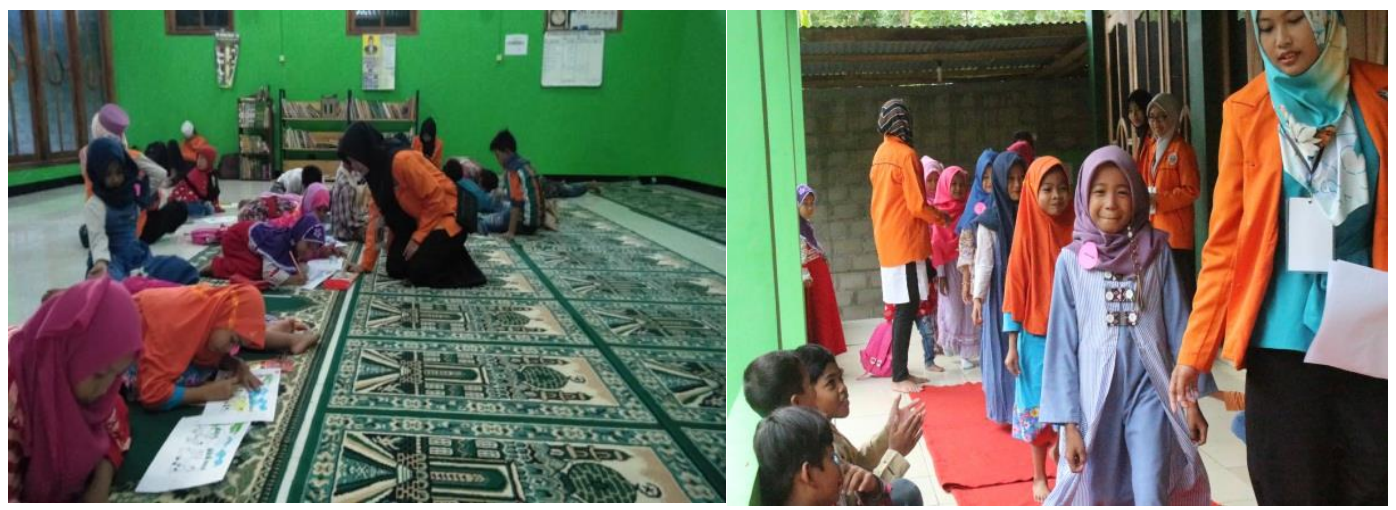

Gambar 3 Kegiatan perlombaan bakat anak

Selain melakukan pendampingan dibidang keagamaan, dilakukan juga pendampingan dan bimbingan untuk memaksimalkan bakat anak. Setiap anak memiliki potensi, minat dan bakat yang berbeda-beda Potensi yang besar pada setiap anak dapat dikembangkan apabila distimulasi dengan baik sehingga kemampuan anak semakin meningkat (Komala, 2017). Keberbakatan tumbuh dari proses interaktif antara lingkungan yang merangsang dan kemampuan pembawaan dan prosesnya (Munandar, 2012).

Bakat anak-anak yang didapati sangat beragam, mulai dari bidang olahraga, seni, keagamaan, dan lain sebagainya. Selain bakat, mereka juga mempunyai minat terhadap bidang yang digeluti. Adanya minat juga akan menguatkan bakat tersebut (Sureni dkk, 2013). Setelah dilakukan pendampingan kemudian dilaksanakan perlombaan dengan tujuan untuk melatih mental anak dan juga membuat anak lebih semangat lagi dalam memaksimalkan potensi yang ada pada diri anak-anak. Perlombaan yang dilangsungkan antara lain lomba menggambar, mewarnai kaligrafi, menyanyi, adzan, hafalan surat, fashion show, dan lain-lain.

\section{Pendampingan Produksi dan Pemasaran Produk Lokal}

Pada dasarnya, masyarakat sudah memiliki kemandirian dalam produksi makanan ringan seperti, keripik pisang, pudding ubi ungu, dan lain-lain. Akan tetapi, bahan baku produksi masih menjadi kendala karena untuk memperoleh bahan baku, masyarakat harus membeli ke luar daerah dengan jarak yang terbilang jauh dan dengan harga yang tidak murah.

Selain itu, masyarakat juga masih mempunyai kendala dalam pemasaran produk. Pemasaran hanya dilakukan dengan cara menitipkan atau menjual produk hasil olahan kepada warung-warung sekitar. Sehingga menyebabkan produk-produk tersebut belum mampu berkembang dan memiliki nilai jual yang rendah, dan masyarakat belum mempunyai keberanian yang tinggi untuk memasarkan produk secara lebih luas, Oleh sebab itu, mahasiswa KKN UAD melakukan pengedukasian dan penyadaran kepada masyarakat. Agar masyarakat menyadari akan potensi merek, sehingga masyarakat mempunyai keberanian untuk memasarkan produk secara lebih luas.

Untuk meningkatkan nilai jual, mahasiswa KKN bersama dengan masyarakat melakukan inovasi baru yaitu Branding produk dengan cara membuat nama dan desain kemasan yang lebih menarik minat pembeli. Branding merupakan salah satu elemen penting yang harus dipertimbangkan ketika merencanakan strategi pemasaran suatu produk. Branding dapat dimanfaatkan untuk menciptakan image sebuah brand dari sebuah produk dalam benak konsumen sehingga diharapkan konsumen mengkonsumsi atau membeli produk tersebut (Diarta dkk, 2016).

Masyarakat juga diberikan edukasi mengenai promosi dan pemasaran yang baik. Dalam melakukan kegiatan promosi oleh penjual (seller) maka dibutuhkan media atau alat-alat yang dapat menunjang kegiatan tersebut (Mardiani \& Imanuel, 2013). Alat yang digunakan oleh 
mahasiswa KKN kepada masyarakat adalah pemanfaatan internet dan social media. Masyarakat diajarkan mengenai pemasaran online atau E-marketing. E-Marketing adalah melakukan bisnis online yang bentuknya paling jelas dengan menjual produk kepada konsumen secara online (Kienan, 2001). Dalam hal ini, masyarakat diberikan cara-cara penggunaan aplikasi media sosial seperti seperti Facebook, Instagram, dan lain sebagainya, untuk menjadikan produk tersebut dikenal lebih luas . Pendampingan produksi dan branding produk terlihat pada gambar 4.

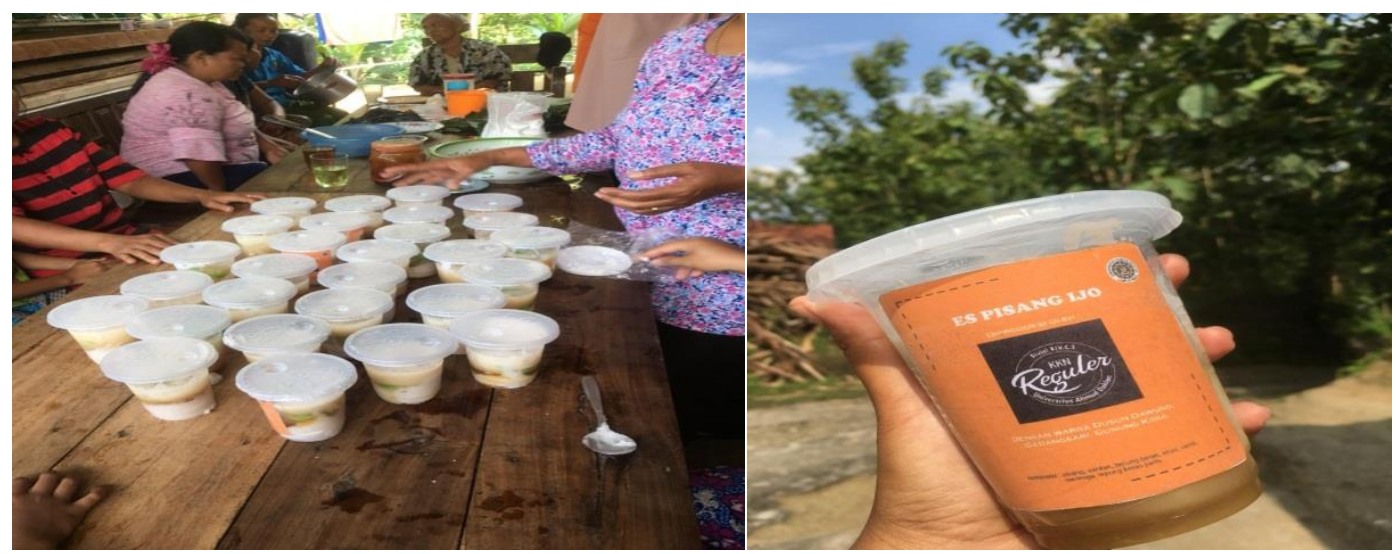

Gambar 4 Pendampingan produksi dan branding produk

Diharapkan dengan adanya hal tersebut, bisa mengubah mindset masyarakat yang semula belum mempunyai keberanian untuk memasarkan potensi secara lebih luas. Setelah diberikan edukasi, masyarakat mampu memasarkan produk secara lebih luas. Dan diharapkan dengan produk tersebut. Dapat meningkatkan perekonomian masyarakat Dusun Serut.

\section{SIMPULAN}

Masyarakat bisa memajukan daerahnya sendiri, terutama untuk memajukan dalam hal ekonomi masyarakat setempat.Pada dasarnya seluruh kegiatan berjalan dengan lancar. Kendala yang dihadapi yaitu untuk mengumpulkan warga, karena di pagi sampai sore masyarakat lebih memilih bekerja. Dan juga waktu KKN yang terbatas, perlu diadakan pendampingan yang berkelanjutan sampai masyarakat benar-benar bisa mandiri untuk mengembangkan potensi yang dimiliki.

\section{DAFTAR PUSTAKA}

Ainiyah, N. (2013). Pembentukan Karakter Melalui Pendidikan Agama Islam. Jurnal Al-Ulun, $13(1), 25-38$.

Darodjat., Wahyudiana. (2014). Memfungsikan Masjid Sebagai Pusat Pendidikan Untuk Membentuk Peradaban Islam. Jurnal ISLAMADINA, XIII(2), 1-13.

Diarta, I. K., S., Lestari, P. W., DeWi, I. A. P. C. (2016). Strategi Branding dalam Promosi Penjualan Produk Pertanian Olahan PT . Hatten Bali untuk Pasar Pariwisata Indonesia. Jurnal Manajemen Agribisnis, 4(2), 170-187.

Kienan, B. (2001). Small Business Solutions E-commerce. Jakarta: Gramedia.

Komala. (2017). Stimulasi Melejitkan Potensi, Minat Dan Bakat Pada Anak Usia Dini.Jurnal Tunas SiliWangi, 3(2), 181-194.

Kurniawan, S. (2014). Masjid Dalam Lintasan Sejarah Umat Islam. Jurnal Khaltulistiwa, 4(2), $169-184$.

Mardiani, I. E.,Imanuel, O. J. (2013). Analisis Keputusan Pembelian Konsumen Melalui Media Online (E-Marketing). Jurnal Ekonomi, 4(2), 151-161. 
Munandar, U. (2012). Pengembangan Kreativitas Anak Berbakat. Jakarta: PT Rineka Cipta.

Muntoha., Jamroni., Jabbar, A. A. (2015). Pemanduan Manajemen Taman Pendidikan AlQur'an (TPA) Di Masjid Arofah, Dusun Bandung Dan Dusun Songbanyu 1, Kecamatan Songbanyu, Gunung Kidul, Daerah Istimewa Yogyakarta. Jurnal Inovasi Dan KeWirausahaan, 4(3), 155-160.

Naafs, S., \& White, B. (2012). Generasi Antara : Refleksi tentang Studi Pemuda Indonesia * Pemuda sebagai Generasi Orang muda adalah aktor kunci dalam. Jurnal Studi Pemuda, I(2), 89-106.

Sureni, S., Herlawati., Supendar, H. (2013). SIstem Pakar Minat Dan Bakat Anak Dengan Multiple Intelligences Berbasis Web. Jurnal Techno Nusa Mandiri, IX(1), 65-77.

Zulmaron, Noupal, M., Aliyah, S. (2017). Peran Sosial Keagamaan Remaja Masjid Di Kelurahan Pipa Reja Kecamatan Kemuning Palembang. JSA, 1(1), 41-54. 
